Original Article

\title{
DETERMINATION OF 4, 4'-BIS (BROMOMETHYL) BIPHENYL GENOTOXIC IMPURITY IN VALSARTAN DRUG SUBSTANCES BY HPLC
}

\author{
S. SENTHIL KUMAR ${ }^{a *}$, RITESH KUMAR SRIVASTAVA ${ }^{b}, V^{\text {. SRINIVASRAOa }}$ \\ aFaculty of Pharmacy, Pacific Academy of Higher Education and Research University, Udaipur-313004, Rajasthan, India, 'bacleod's \\ Pharmaceuticals Limited, R\&D center, Andheri-400059, Mumbai, India
}

Email: chensenk@gmail.com

Received: 10 Aug 2016 Revised and Accepted: 09 Sep 2016

\begin{abstract}
Objective: The objective of the present study was to develop and validate a specific and sensitive analytical method, which separate the genotoxic impurity 4, 4'-bis (bromomethyl) biphenyl from valsartan antihypertensive drug substance using HPLC method.

Methods: The development activity was conducted by HPLC with UV detector. The impurity was separated on Inertsil ODS 3V 250 x $4.6 \mathrm{~mm}, 5 \mu \mathrm{m}$ analytical column with a mobile phase consisting of $5.5 \mathrm{pH}$ buffer and acetonitrile with the gradient program at a flow rate $1.0 \mathrm{ml} / \mathrm{min}$. The effluent was detected using UV detector attached with HPLC system at $275 \mathrm{~nm}$ meanwhile column temperature and injection volume was maintained to 35 ${ }^{\circ} \mathrm{C}$ and $50 \mu \mathrm{l}$ respectively. Acetonitrile was selected as diluent for performing the experiment.
\end{abstract}

Results: Whole experiment and validation process was performed as per the ICH guideline. The LOD and LOQ value were found to be $0.153 \mu \mathrm{g} / \mathrm{g}$ and $0.463 \mu \mathrm{g} / \mathrm{g}$ respectively, while accuracy results were well in the range 97.62 to $104.59 \%$. The linearity curve showed a correlation coefficient of 0.9994 and method was very sensitive.

Conclusion: From validation data, it was confirmed that the developed method is specific, sensitive, linear, precise and accurate for the determination of 4, 4'-bis (bromomethyl) biphenyl genotoxic impurity in valsartan drug substances.

Keywords: Impurity, HPLC, TTC, Validation, ICH guidelines

(C) 2016 The Authors. Published by Innovare Academic Sciences Pvt Ltd. This is an open access article under the CC BY license (http://creativecommons.org/licenses/by/4. 0/) DOI: http://dx.doi.org/10.22159/ijpps.2016v8i11.14614

\section{INTRODUCTION}

Pharmaceutical industries strictly follows FDA and ICH guidelines for new drug development which includes characterization of several physical and chemical properties prior to starting licensing process [1, 2]. Among those essential criterions, the genotoxic impurities determination (GTIs) in pharmaceutical products is a most important significant factor and has received considerable attention in recent years. Under section Q3A of an international conference on harmonization provides very clear guidelines on impurities in new drug substances [3]. According to these guidelines, lowering reporting thresholds can be appropriate if the impurity is unusually toxic while European Medicines Agency (EMEA) issued guidelines for GTI limits and included the concept of threshold toxicological concern (TTC) to define acceptable risk for the new active substances [4]. Pharmaceutical genotoxic impurities may potentially increase the risk of cancer in patients.

Valsartan is an orally active, potent, non-peptide drug that belongs to a class of antihypertensive agents called angiotensin II receptor blockers [5]. The drug has more affinity about 20,000-fold for the angiotensin type 1 receptor than for the angiotensin type 2 receptor, through relaxing blood vessels and causing them to extend, leads to lowers blood pressure and improves the blood flow [6, 7]. The drug is rapidly orally absorbed, the limited volume of distribution, extensively bound to plasma proteins, relaxes to control high blood pressure and congestive heart [8]. The half-life of the drug is very short (3-7 h). It works by blocking a substance in the body that causes blood vessels to tighten [9]. Valsartan is a lipophilic drug and is effective in the treatment of hypertension, pediatric, adolescents and the elderly patients with mild to moderate hypertension [10-12]. The drug product is available in the market either individually or combination with other drugs in different trade names i.e. Diovan, Valfect, Starval, Valent, Valent-R, Co-Diovan, Exforge, Entresto, Valzaar, Nebicard-V and manufactured by various pharmaceutical industries.

Valsartan \{3-Methyl-2- [pentanoyl-[[4-[2-(2H-tetrazol-5-yl) phenyl] phenyl] methyl] amino]-butanoic acid $\}$ is a tetrazole derivative containing carboxylic groups and shows weak acidic nature [13, 14]. The molecule belongs to low solubility and high permeability class II type as per biopharmaceutics classification system [15]. Many potential impurities arise during the synthesis of valsartan. The amount of theses impurities present in drug substances determines the safety of the drug product. Therefore identification, quantification and control of impurities are now a crucial part of drug development. Chromatographic impurity profiles are most often developed using RP-HPLC. The chromatographic impurity profile should allow detecting and separating all identified and unidentified impurities in each new active compound.

The deeply rooted literature survey reveals that synthetic impurities of valsartan content have been determined by LC-MS [16-18], UPLC [19], GC [20], HPTLC [21] and HPLC [22-24] analytical techniques but up to yet no any method is available for the determination of 4,4'-bis (bromomethyl) biphenyl genotoxic impurity in valsartan drug substances.

The evaluation limits for potential genotoxic impurities in the valsartan was calculated based on TTC and a maximum daily dose of drug i.e. $320 \mathrm{mg}$. A maximum daily exposure target of genotoxic impurities is $1.5 \mu \mathrm{g}$ per day per person $[2,4]$.

Evaluation Limits $(\mu \mathrm{g} / \mathrm{g})=\frac{1.5 \mu \mathrm{g} / \text { day }}{\text { dailydose }(\mathrm{g} / \text { day })}=\frac{1.5}{0.320}=4.68 \mu \mathrm{g} / \mathrm{g}$

Hence $4.68 \mu \mathrm{g} / \mathrm{g}$ is the evaluation limit of potentially genotoxic impurities for valsartan drug.

Valsartan has molecular formula $\mathrm{C}_{24} \mathrm{H}_{2} \mathrm{~N}_{5} \mathrm{O}_{3}$, molecular weight 435.52 and pKa value 4.9. The chemical structure of valsartan and 4,4'-bis (bromomethyl) biphenyl genotoxic impurity is given in fig. 1. Because of literature gap for the determination of 4,4'-bis (bromomethyl) biphenyl genotoxic impurity, we have reported here in a specific and sensitive analytical method, which separates the impurity from the drug substances and also could quantify the impurity at less than $50 \%$ to the evaluation limit. 
<smiles>CCCCC(=O)N(Cc1ccc(-c2ccccc2-c2nnn[nH]2)cc1)[C@@H](C(=O)O)C(C)C</smiles>

(a)<smiles>BrCc1ccc(-c2ccc(CBr)cc2)cc1</smiles>

(b)
Fig. 1: Chemical structure of (a) Valsartan and (b) 4, 4'-bis (bromomethyl) biphenyl

\section{MATERIALS AND METHODS}

\section{Chemicals and reagents}

Water (HPLC grade), orthophosphoric acid, methanol, triethylamine and acetonitrile were purchased from Merck, India. All pure drug substances and impurities are used for research purpose were procured in-house Macleods pharmaceutical LTD, India.

\section{Instrumentation}

While performing method development and method validation

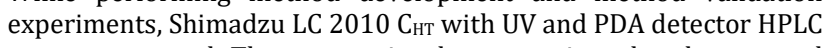
system was used. The output signal was monitored and processed using LC solution software (version 1.12). The $\mathrm{pH}$ of the buffer was adjusted by using digital $\mathrm{pH}$ meter, Model Pico+made in lab India. An analytical balance model MSU225P-100-DU made in Sartorius,
Germany, and an ultrasonic bath model 9L250H made in lab devices; India was used to perform the experiments.

\section{Chromatographic conditions}

The chromatographic separation was achieved on a gradient method using Inertsil ODS 3V, $250 \mathrm{~mm} \times 4.6 \mathrm{~mm}, 5 \mu \mathrm{m}$ particle size HPLC column. The mobile phase A buffer pH $5.0 \quad(1.0 \mathrm{ml}$ of orthophosphoric acid in $1000 \mathrm{ml}$ water, adjust $\mathrm{pH} 5.0$ with triethylamine) and the acetonitrile as mobile phase $\mathrm{B}$. The flow rate of mobile phase was $1.0 \mathrm{ml} / \mathrm{min}$. The HPLC gradient program set as, time (min) $/ \%$ mobile phase B: $(0.01 / 60)(30 / 60)(35 / 80)(40 / 80)$ $(41 / 60)$ and $(45 / 60)$. The column temperature was maintained at $35{ }^{\circ} \mathrm{C}$ and the detection was monitored at $275 \mathrm{~nm}$. The injection volume was $50 \mu \mathrm{l}$ and acetonitrile was selected as diluent.

\section{Preparation of standard and sample solutions}

A stock solution of 4,4'-bis (bromomethyl) biphenyl impurity was prepared by dissolving the appropriate amount of 4,4'-bis (bromomethyl) biphenyl impurity in diluents. The working concentration of $0.23 \mu \mathrm{g} / \mathrm{ml}$ impurity solution were prepared from the stock solution and used as a standard solution. The sample solution $(50000 \mu \mathrm{g} / \mathrm{ml})$ were prepared by weighing $500 \mathrm{mg}$ of drug substances and transferred to $10 \mathrm{ml}$ volumetric flask.

\section{RESULTS AND DISCUSSION}

\section{Method development}

The method was developed by taking cognition to the main parameters like the selection of wavelength, HPLC column, mobile phase, column oven temperature, flow rate, injection volume and diluent. The standard solution was prepared and injected into HPLC system with PDA detector, and a spectrum was obtained. The maximum absorption wavelength of the solution was shown at about $274.56 \mathrm{~nm}$ (fig. 2). Hence $275 \mathrm{~nm}$ was selected for the quantification of this impurity in the valsartan drug substances.

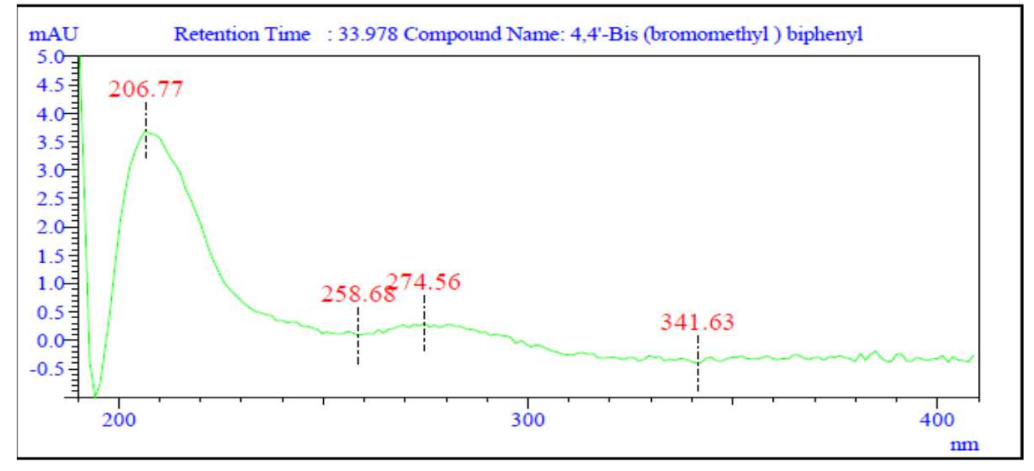

Fig. 2: Absorption spectrum of 4, 4'-Bis (bromomethyl) biphenyl

The selection of HPLC column carried out by conducted trials on various packaging material of ODS, C8 and C18 in different length, internal diameter, particle size and pore size manufactured by different industries. After performing trials on the column the decisively separation was accomplished on GL sciences manufactured HPLC column i.e. Inertsil ODS 3V ( 250 x $4.6 \mathrm{~mm}) 5 \mu \mathrm{m}$.

The selection of mobile phase was carried out on isocratic condition by prepared water as mobile phase $\mathrm{A}$ and acetonitrile as mobile phase $B$ in the ratio $50: 50 \mathrm{v} / \mathrm{v}$ and the standard solution of impurity was injected. The result was observed that the analyte peak was not eluted within $60 \mathrm{~min}$. The trail was continued by applied gradient condition with the same mobile phase result was observed that peak shape of analyte was not proper with noisy baseline and the pharmacopeial/process impurities were co-eluted along with the main peak. After performing many trials with experimental data the chromatographic separation was finalized by the following gradient program (Time/\% Solution B) was fixed as $(0.01 / 60)(30 / 60)$ $(35 / 80)(40 / 80)(41 / 60)$ and $(45 / 60)$ by using buffer $\mathrm{pH} 5.0(1.0 \mathrm{ml}$ of orthophosphoric acid in $1000 \mathrm{ml}$ water, adjust pH 5.0 with triethylamine) and acetonitrile were used as Mobile Phase A and B.

The column temperature was selected by taking many trials with different column oven temperature $\left(20^{\circ} \mathrm{C}\right.$ to $\left.55^{\circ} \mathrm{C}\right)$. The analyte was well separated and the reproducible result was obtained at $35^{\circ} \mathrm{C}$.

The flow rate of the mobile phase was optimized from $0.5-1.5$ $\mathrm{ml} / \mathrm{min}$ for separation of analyte peak from blank and impurities peaks. It was found from the experiments that $1.0 \mathrm{ml} / \mathrm{min}$ flow rate was ideal for the successful elution of the compound.

The standard solution was injected from $10 \mu \mathrm{l}$ to $100 \mu \mathrm{l}$ injection volume into HPLC system. Based on the response and shape of the peak $50 \mu$ injection volume was selected.

For the selection of diluent the solubility was checked for Valsartan, 4,4'-Bis (bromomethyl) biphenyl and other impurities in water, methanol, acetonitrile, mobile phase $A$ and the combination of water: methanol, water: acetonitrile and mobile phase A: acetonitrile 
in different ratio. Valsartan, 4,4'-bis (bromomethyl) biphenyl and other impurities having a good solubility in acetonitrile than others are diluent. Hence, acetonitrile was selected diluent.

\section{Method validation}

The developed HPLC method has been validated for genotoxic impurity determination in valsartan sample as per ICH guideline [25]. The individual parameter of system suitability, specificity, limit of detection, limit of quantification, linearity and range, precision, accuracy, solution stability and robustness was experimentally evaluated by injected standard and sample solution.

\section{System suitability}

According to USP [26], system suitability test is an integral part of liquid chromatographic methods to verify that the system is adequate for the analysis. The standard solution was prepared, and $50 \mu \mathrm{L}$ of six replicates was injected into HPLC system. The obtained peak was calculated for the theoretical plates, tailing factor and $\%$
RSD of six replicate areas and the result was found to comply with USP requirements. The results are present in table 1 and chromatogram was presented in fig. 3.

\section{Specificity}

For demonstrating the specificity of the method blank, pharmacopeial listed/process impurities, 4,4'-bis (bromomethyl) biphenyl standard, valsartan sample were prepared individually at specification limit in the diluent and the solution of valsartan spiked with 4,4'-bis (bromomethyl) biphenyl at evaluation limit and injected into developed chromatographic condition. No chromatographic interference (fig. 4) from any of the blank, impurities and sample peak was found at the retention time of 4,4'-bis (bromomethyl) biphenyl.

These results (table 1) confirm the specificity of the method without any interfering peak around the retention time of 4,4'-bis (bromomethyl) biphenyl; also the baseline did not show any significant noise. Prabhu and Muralidhar reported the interference study in irbesartan antihypertensive drug substances [27].

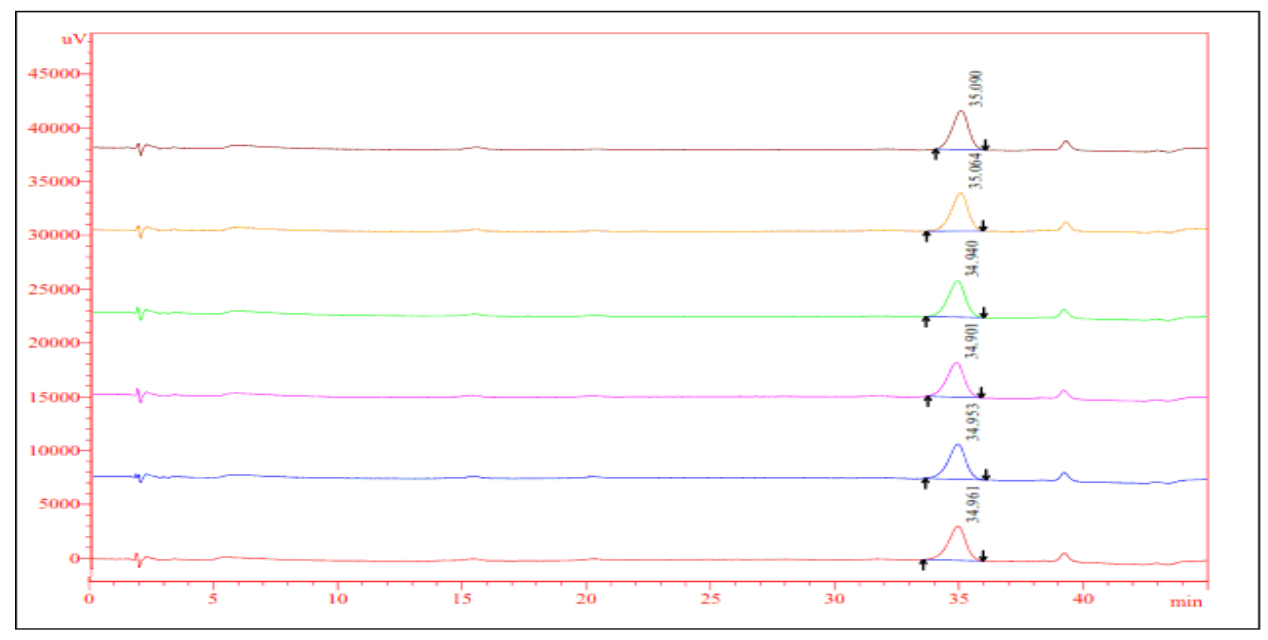

Fig. 3: Overlay chromatograms of replicate standard injections

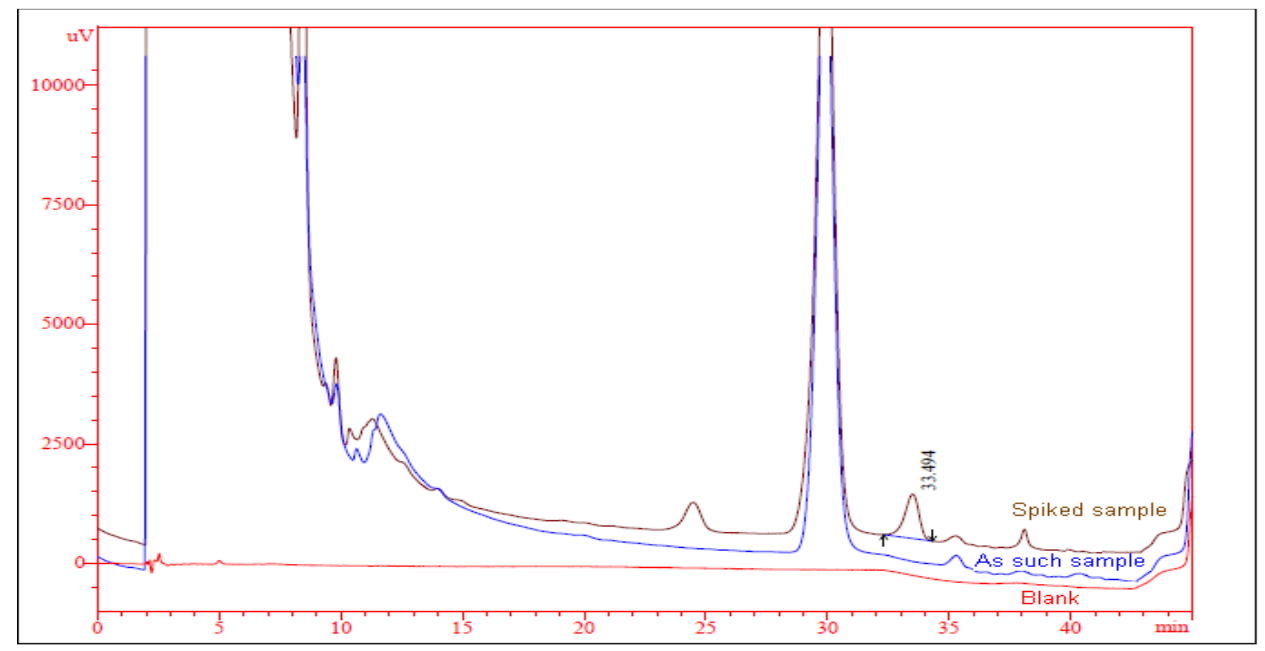

Fig. 4: Overlap chromatogram of blank, sample and spiked sample

\section{Limit of detection and limit of quantitation}

The LOD and LOQ for 4,4'-bis (bromomethyl) biphenyl were estimated through signal-to-noise ratio of 3:1 and 10:1 respectively, by injecting a series of dilute solutions having known concentrations [20,24]. LOD of the impurity is defined as the lowest concentration that can be detected. LOD was found to be $0.153 \mu \mathrm{g} / \mathrm{g}$ (fig. 5). LOQ is the lowest concentration that can be quantified with acceptable precision and accuracy. LOQ was found to be $0.463 \mu \mathrm{g} / \mathrm{g}$ (fig. 6).

The low values of LOD and LOQ indicates the adequate sensitivity of the method. The precision study was also carried out at LOQ level by injecting six individual preparations and calculating the \% RSD of the area. The results are present in table 1. 
Table 1: Validation results

\begin{tabular}{|c|c|c|c|c|}
\hline Parameters & \multicolumn{2}{|c|}{ Acceptance criteria } & \multicolumn{2}{|l|}{ Results } \\
\hline \multirow[t]{3}{*}{ System Suitability } & \multicolumn{2}{|c|}{ The theoretical plates in standard solution NLT 2000} & \multicolumn{2}{|l|}{2184} \\
\hline & \multicolumn{2}{|c|}{ The tailing factor in standard solution NMT 2.0} & \multicolumn{2}{|l|}{1.24} \\
\hline & \multicolumn{2}{|c|}{ The \% RSD in standard solution NMT $5.0 \%$} & \multicolumn{2}{|l|}{1.78} \\
\hline \multirow[t]{7}{*}{ Specificity } & No interference & Blank & \multirow[t]{7}{*}{ Retention time } & No Peak \\
\hline & & Impurity-A & & $2.99 \mathrm{~min}$ \\
\hline & & Impurity-B & & $8.89 \mathrm{~min}$ \\
\hline & & Impurity-C & & $2.88 \mathrm{~min}$ \\
\hline & & 2-Cyano-4'-bromomethyl biphenyl & & $14.12 \mathrm{~min}$ \\
\hline & & Valinate acid & & $5.62 \mathrm{~min}$ \\
\hline & & 4, 4'-Bis (bromomethyl) biphenyl & & $34.96 \mathrm{~min}$ \\
\hline Limit of Detection and & LOD concentrati & & \multicolumn{2}{|l|}{0.153} \\
\hline \multirow[t]{4}{*}{ Limit of Quantitation } & \multicolumn{2}{|c|}{$\mathrm{S} / \mathrm{N}$ ratio LOD should be $3: 1$} & \multicolumn{2}{|l|}{3.87} \\
\hline & \multicolumn{2}{|c|}{ LOQ concentration $(\mu \mathrm{g} / \mathrm{g})$} & \multicolumn{2}{|l|}{0.463} \\
\hline & \multicolumn{2}{|c|}{ S/N ratio LOD should be $10: 1$} & \multicolumn{2}{|l|}{12.48} \\
\hline & \multicolumn{2}{|c|}{ \% RSD at LOQ level should NMT $10.0 \%$} & \multicolumn{2}{|l|}{2.76} \\
\hline \multirow{2}{*}{$\begin{array}{l}\text { Linearity } \\
\text { and }\end{array}$} & \multicolumn{2}{|c|}{ Slope (Record Results) } & \multicolumn{2}{|l|}{6820.97} \\
\hline & \multicolumn{2}{|c|}{ Intercept (Record Results) } & \multicolumn{2}{|l|}{395.01} \\
\hline \multirow[t]{3}{*}{ Range } & \multicolumn{2}{|c|}{ Correlation Coefficient (NLT 0.990) } & \multicolumn{2}{|l|}{0.9994} \\
\hline & \multicolumn{2}{|c|}{ Residual sum of square (Record Results) } & \multicolumn{2}{|l|}{1476929.33} \\
\hline & \multicolumn{2}{|c|}{ Range (Record Results) } & \multicolumn{2}{|c|}{$0.463 \mu \mathrm{g} / \mathrm{g}$ to $7.066 \mu \mathrm{g} / \mathrm{g}$} \\
\hline \multirow[t]{2}{*}{ Precision } & $\%$ RSD of repeat & JMT $10.0 \%$ & $0.30 \%$ & \\
\hline & $\%$ RSD of Interm & on study NMT $10.0 \%$ & $0.33 \%$ & \\
\hline Solution stability & Absolute differe & y should be not more than $15 \%$ of evaluation limit & Complies & \\
\hline Robustness & Deliberate chan & loped condition should not impact on system suitability & Complies & \\
\hline
\end{tabular}

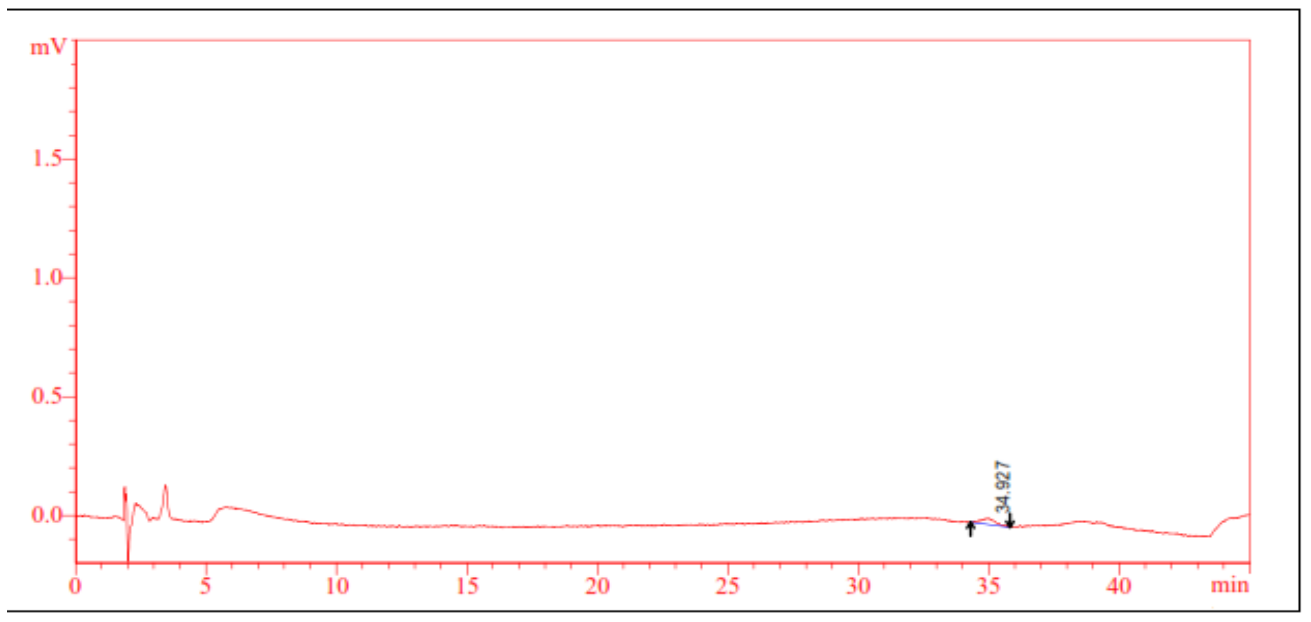

Fig. 5: Limit of detection chromatogram

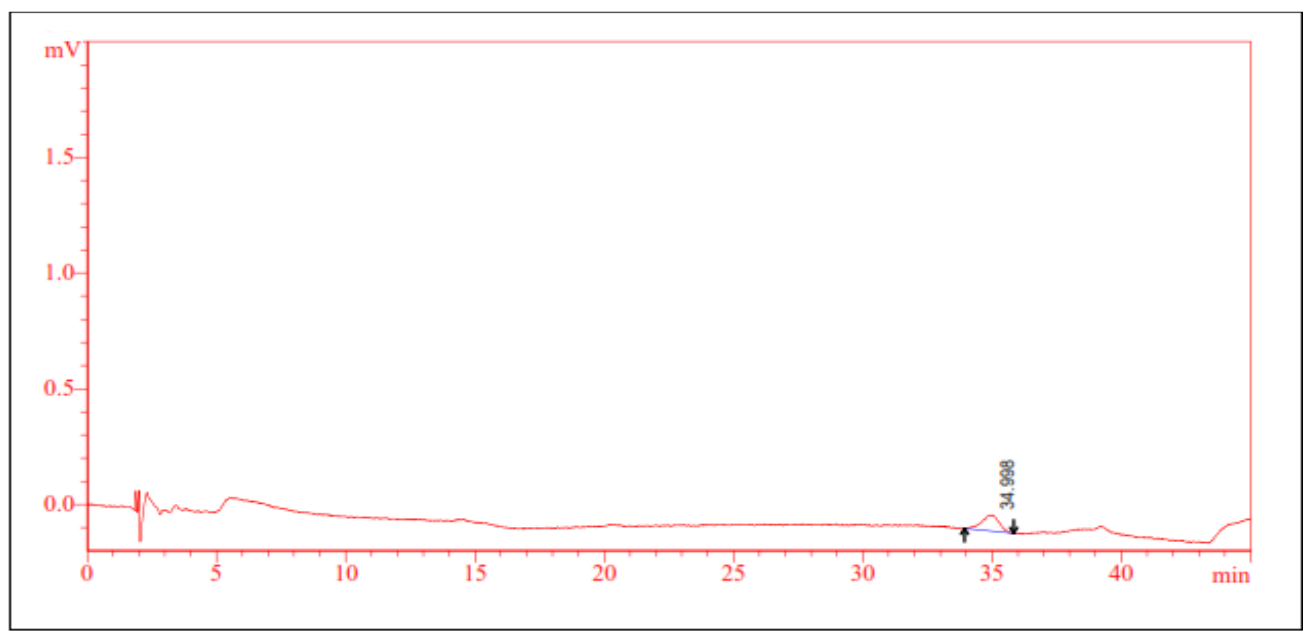

Fig. 6: Limit of quantitation chromatogram 


\section{Linearity and range}

To establish the linearity of the developed method, calibration solution were prepared by diluting the impurity stock solution to obtain solutions at LOQ (10\%), $50 \%, 80 \%, 100 \%, 120 \%$ and 150 $\%$ from the evaluation limits. Each solution was injected, and area of responses was recorded at $275 \mathrm{~nm}$. The graph of peak area vs concentration in $\mu \mathrm{g} / \mathrm{g}$ was plotted (fig. 7). The slope, intercept, correlation coefficient of the regression line and residual sum of the square were calculated. The correlation coefficient obtained was greater than 0.990 . The result shows that an excellent correlation existed between the peak area and the concentration of the impurity $[24,27]$. The results are summarized in table 1 and chromatogram was presented in fig. 8 .

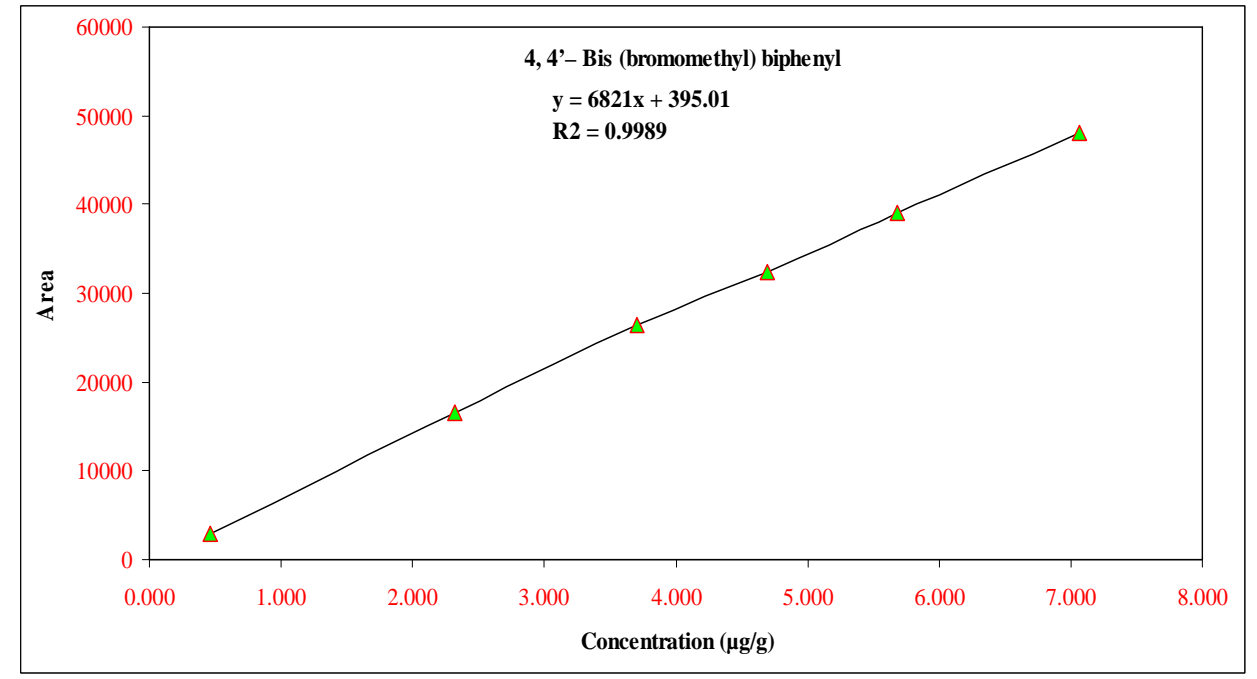

Fig. 7: Linearity of 4,4'-bis (bromomethyl) biphenyl

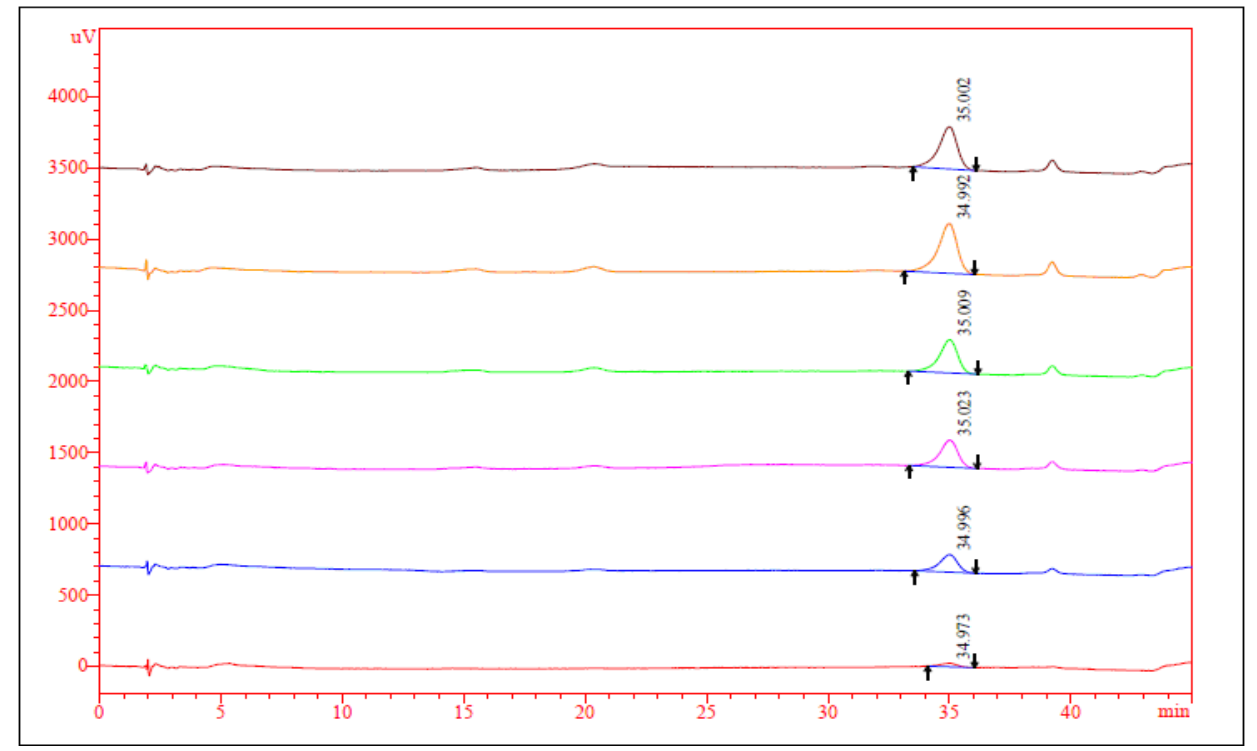

Fig. 8: Linearity chromatogram (Level-1 to Level-6)

\section{Precision}

Precision was determined through repeatability and intermediate precision, Precision of the method was checked by injecting six individual preparation of Valsartan spiked with the impurity at evaluation limit. The percentage RSD of the content of impurity was calculated. Intermediate precision of the method was evaluated by injecting six individual preparation of the spiked sample at evaluation limit on a different day in the same laboratory. The \% RSD for the content of 4,4'-bis (bromomethyl) biphenyl impurity was very low, confirming the high precision of the method [20]. The results are present in table 1.

\section{Accuracy}

The accuracy of the method was determined by analyzing the drug substances spiked with impurity. A known amount of impurity was spiked to the valsartan sample at different concentration levels of LOQ $50 \%, 100 \%$ and $150 \%$ of the evolution limit. Each concentration level was prepared in triplicate. The percentage recovery of impurity in the drug substances was calculated. The recovery of the 4,4'-bis (bromomethyl) biphenyl in valsartan ranged from 97.62 to $104.59 \%$ which is well within acceptance criteria $80 \%$ to $120 \%$ [20]. The low value of $\%$ RSD is confirming that the method is accurate. The results are summarized in table 2 and chromatogram was presented in fig. 9. 


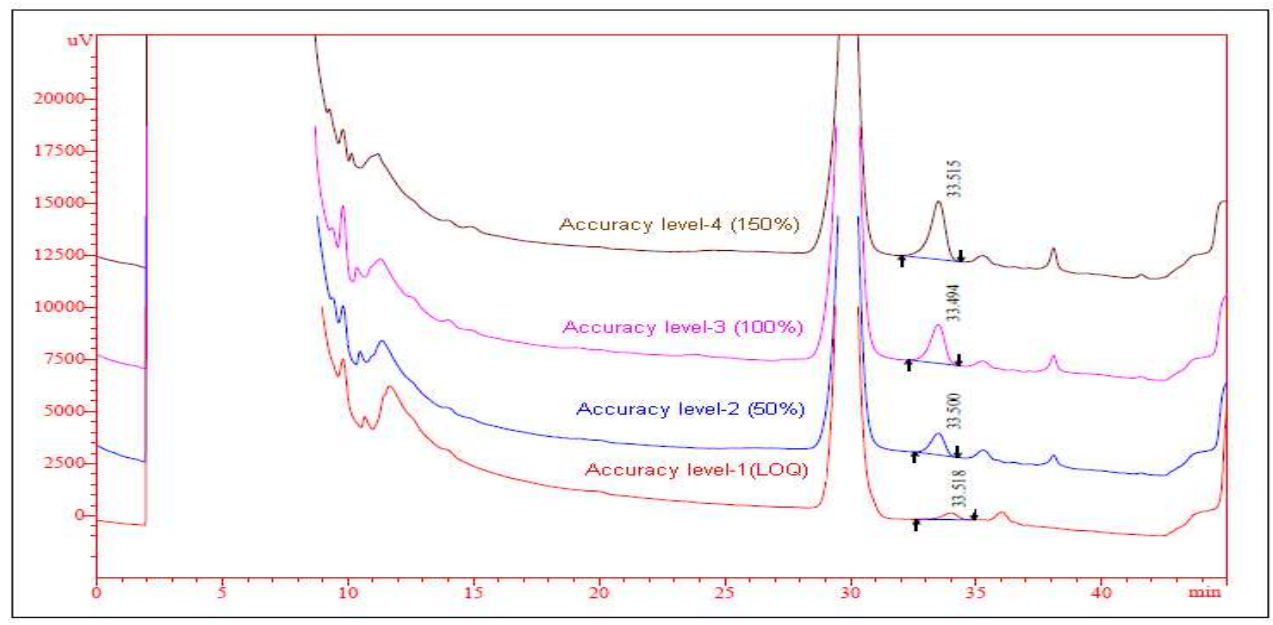

Fig. 9: Overlay chromatogram of accuracy at LOQ, 50, 100 and $150 \%$

Table 2: Accuracy at different spiking concentration

\begin{tabular}{|c|c|c|c|c|}
\hline Level & Amount in sample & Amount added in $(\mu \mathrm{g} / \mathrm{g})$ & Amount found in $(\mu \mathrm{g} / \mathrm{g})$ & Recovery (\%) \\
\hline \multirow[t]{3}{*}{ At LOQ } & nil & 0.464 & 0.457 & 98.92 \\
\hline & nil & 0.463 & 0.464 & 100.43 \\
\hline & nil & 0.462 & 0.451 & 97.62 \\
\hline \multirow[t]{3}{*}{$50 \%$} & nil & 2.312 & 2.336 & 101.13 \\
\hline & nil & 2.314 & 2.324 & 100.61 \\
\hline & nil & 2.316 & 2.351 & 101.77 \\
\hline \multirow[t]{3}{*}{$100 \%$} & nil & 4.622 & 4.659 & 100.82 \\
\hline & nil & 4.625 & 4.632 & 100.24 \\
\hline & nil & 4.621 & 4.627 & 100.13 \\
\hline \multirow[t]{6}{*}{$150 \%$} & nil & 6.932 & 6.998 & 100.97 \\
\hline & nil & 6.935 & 6.914 & 99.75 \\
\hline & nil & 6.931 & 7.249 & 104.59 \\
\hline & & & Mean & 100.47 \\
\hline & & & SD & 1.70 \\
\hline & & & $\%$ RSD & 1.69 \\
\hline
\end{tabular}

\section{Solution stability}

The solution stability was established by spiking 4,4'-Bis (bromomethyl) biphenyl impurity in valsartan sample. The prepared solution was stored at room temperature for $24 \mathrm{~h}$. The content of impurity was determined at $4 \mathrm{~h}$ interval for $24 \mathrm{~h}$. The result was observed that no significant change in the content of the impurity.

\section{Robustness}

To determine the robustness of the method the experimental conditions were deliberately altered and the system suitability result was evaluated. To study the effect of flow rate, it was changed by 0.2 units from $1.0 \mathrm{ml} / \mathrm{min}$ to $0.8 \mathrm{ml} / \mathrm{min}$ and $1.2 \mathrm{ml} / \mathrm{min}$. The effect of column temperature was studied by changed $5{ }^{\circ} \mathrm{C}$ units from $35{ }^{\circ} \mathrm{C}$ to $30{ }^{\circ} \mathrm{C}$ and $40{ }^{\circ} \mathrm{C}$. The results were found that the deliberate changes in the method i.e. flow rate of mobile phase and column oven temperature has no impact on system suitability [23].

\section{Batch analysis}

The three production batches of valsartan drug substance were analyzed in the validated method for determination of 4, 4'-bis (bromomethyl) biphenyl and found the impurity was not detected in all three batches. The chromatogram was presented in fig. 10.

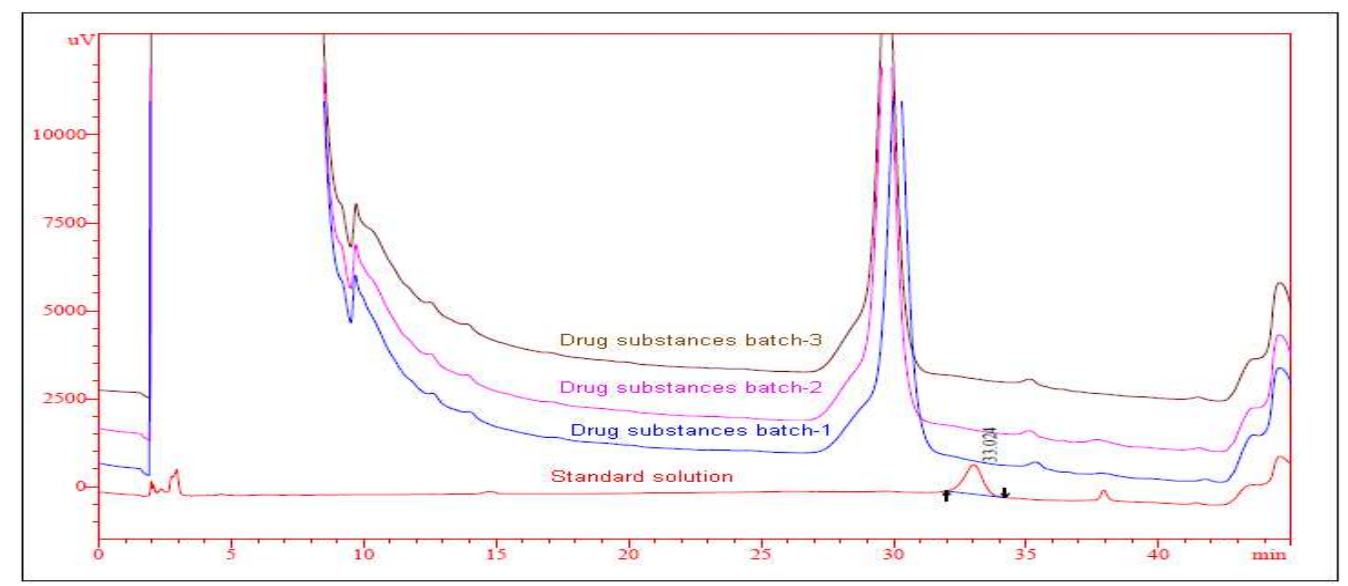

Fig. 10: Overlap chromatogram of three production batches of valsartan sample with standard solution 


\section{CONCLUSION}

The gradient HPLC method developed for the trace level quantitative determination of genotoxic 4,4'-bis(bromomethyl)biphenyl in Valsartan is linear, precise, accurate, rugged and robust. Satisfactory results were obtained from validation of the method as per ICH guideline. This method exhibited an excellent performance in terms of sensitivity and specificity with no sample matrix and impurity interference observed. The sample prepared in analytical solution is found to be stable for $24 \mathrm{~h}$. This method can be used for routine analysis of the trace level quantitative determination of 4, 4'-bis (bromomethyl) biphenyl in Valsartan drug substances.

\section{ACKNOWLEDGEMENT}

The authors wish to thank the management of Macleods pharmaceutical Ltd., India for supporting this work.

\section{CONFLICT OF INTERESTS}

\section{Declared none}

\section{REFERENCES}

1. Genotoxic and carcinogenic impurities in drug substances and products: Recommended approached. US department of health and human services, Food and Drug Administration, Center for Drug Evaluation and Research (CDER); 2008.

2. International conference on harmonization, Assessment, and control of DNA reactive (Mutagenic) impurities in pharmaceuticals to limit potential carcinogenic risk M7; 2014.

3. International conference on harmonization, Q3A (R2) Impurities in new drug substances: Text and Methodology; 2006.

4. European medicines agency evaluation of medicines for human use, guideline on the limits of genotoxic impurities; 2006.

5. Magda IM. Investigation on thermal stability and purity determination of two antihypertensive drugs, valsartan and losartan potassium. Int J Curr Pharm Res 2015;7:64-9.

6. William HF, Angela CL, James N. Current cardiovascular drugs. 4th ed. New York: Edwards brothers Inc publisher; 2005. p. 59-60.

7. Mclnnes GT. Clinical advantage of valsartan, Cardiology 1999;91:14-8.

8. Oparil S, Dyke S, Harris F, Kief J, James D, Hester A, et al. The efficacy and safety of valsartan compared with placebo in the treatment of patients with essential hypertension. Clin Ther 1996;18:797-810.

9. Gadepallia SG, Demeb P, Kunchaa M, Sistlaa R. Simultaneous determination of amlodipine, valsartan and hydrochlorothiazide by LC-ESI-MS/MS and its application into pharmacokinetics in rats. J Pharm Anal 2014;4:399-406.

10. Shetiya P, Vidyadhara S, Ramu A, Sasidhar RL, Viswandh K. Development and characterization of a novel nanosuspension based drug delivery system of valsartan: a poorly soluble drug. Asian J Pharm 2015;9:29-34.

11. Nadeem S, Asif H, Lakshita C, Alam MS, Mitra M, Bhasin PS, et al. Pharmacological and pharmaceutical profile of valsartan: a review. J Appl Pharm Sci 2011;1:12-9.

12. Bhavani PD, Rao NGR. Formulation and evaluation of valsartan fast disintegrating tablets by vaccume drying technique. Asian J Pharm Clin Res 2016;9:73-9.

13. Thomas U, Bernward AS. Angiotensin Vol. II. New York: Springer-berlin heidelberg; 2004. p. 420-40.
14. Croom KF, Keating GM. Valsaratn: a review of its use in patients with heart failure and/or left ventricular systolic dysfunction after myocardial infarction. Am J Cardiovasc Drugs 2004;4:395404.

15. Jain H, Pasha TY, Bais CS, Bhandari A. Formulation and characterization of liquid-solid tablets of valsartan for improvement of dissolution rate. Asian J Pharm Clin Res 2014;7:21-6.

16. Reddy MY, Ramesh V, Reddy CK, Venugopal N, Sarevanan G, Suresh Y, et al. Low-level determination of residual 4-bromo methyl-2'-cyanobiphenyl in valsartan by liquid chromatography-mass spectrometry. Asian J Res Chem 2010;3:407-510.

17. Shah HJ, Kataria NB, Subbaiah G, Patel CN. Simultaneous LCMS-MS analysis of valsartan and hydrochlorothiazide in human plasma. Chromatographia 2009;69:1055-60.

18. Hao L, Wang Y, Jiang Y, Tang Y, Wang J, Zhao L, et al. A liquid chromatography/tandem mass spectrometry method for the simultaneous quantification of valsartan and hydrochlorothiazide in human plasma. J Chromatogr B: Anal Technol Biomed Life Sci 2007;852:436-42.

19. Vojta J, Jedlicka A, Coufal P, JaneckovaL. A new rapid stabilityindicating UPLC method for separation and determination of impurities in amlodipine besylate, valsartan and hydrochlorothiazide in their combined tablet dosage form. J Pharm Biomed Anal 2015;109:36-44.

20. Reddy GA, Reddy KH, Kumar MN, Sharma HK. Simple and sensitive methods for the determination of 2-(4'-chloromethyl phenyl) benzonitrile and 2-(4'-bromomethyl phenyl) benzonitrile contents in valsartan drug substance by gas chromatography. ISRN Anal Chem 2013;1-5. http://dx.doi.org/10.1155/2013/542516

21. Monika LJ, Manoj VG, Shripad KT. Development and validation of HPTLC method for simultaneous estimation of valsartan and hydrochlorothiazide in tablet dosage form. J Pharm Biosci 2015;3:20-5.

22. Tian DF, Tian XL, Tian T, Wang ZY, Mo FK. Simultaneous determination of valsartan and hydrochlorothiazide in tablets by RP-HPLC. Indian J Pharm Sci 2008;70:372-4.

23. Jalhan S, Kotach M, Jian UK. Development and validation of analytical method for the estimation of a combination of pravastatin sodium and valsartan by reversed phase-high performance liquid chromatography. Asian J Pharm Clin Res 2016;9:372-7.

24. Pradhan KK, Mishra US. Development and validation of a stability indication RP-HPLC method for the determination of valsartan. Int J Pharm Pharm Sci 2015;7:57-61.

25. International conference on harmonization, Q2 (R1) Validation of analytical procedures: Text and methodology; 2005.

26. United States Pharmacopoeia. General chapter $<621>$ "Chromatography", USP 37, NF 32; 2014.

27. Prabhu P, Muralidhar M. Development and validation of a highperformance liquid chromatography method for simultaneous determination of irbesartan and its related impurities in pharmaceutical tablets. Int J Pharm Sci Drug Res 2014;6:145-53.

\section{How to cite this article}

- S Senthil Kumar, Ritesh Kumar Srivastava, V Srinivasrao. Determination of 4,4'-bis(bromomethyl) biphenyl genotoxic impurity in valsartan drug substances by HPLC. Int J Pharm Pharm Sci 2016;8(11):209-215. 